\title{
The influence of an ITER-like wall on disruptions at JET
}

P.C. de Vries ${ }^{1}$, M. Baruzzo ${ }^{2}$, G.M.D. Hogeweij ${ }^{1}$, S. Jachmich ${ }^{3}$, E. Joffrin ${ }^{4}$, P.J. Lomas ${ }^{5}$, G.F. Matthews ${ }^{5}$, A. Murari ${ }^{2}$, I. Nunes ${ }^{6}$, T. Pütterich ${ }^{7}$, C. Reux $^{4}$, J. Vega $^{8}$ and JET-EFDA Contributors*

JET-EFDA Culham Science Centre, Abingdon, OX14 3DB, UK

${ }^{1}$ FOM institute DIFFER, EURATOM association, P.O. Box 1207, Nieuwegein, Netherlands

${ }^{2}$ Consorzio RFX, EURATOM-ENEA Association, Corso Stati Uniti 4, 35127 Padova, Italy

${ }^{3}$ ERM/KMS, Association EURATOM-Belgian State, B-1000 Brussels, Brussels, Belgium

${ }^{4}$ IRFM-CEA, Centre de Cadarache, 13108 Sant-Paul-lez-Durance, France

${ }^{5}$ CCFE/Fusion Association, Culham Science Centre, Abingdon, OX14 3DB, UK

${ }^{6}$ Associação EURATOM-IST, Instituto de Plasmas e Fusão Nuclear, 1049-001 Lisboa, Portugal

${ }^{7}$ Max-Planck-Institut für Plasmaphysik, EURATOM Association, 85748 Garching, Germany

${ }^{8}$ Asociación EURATOM/CIEMAT para Fusión. Madrid, Spain

*F. Romanelli et al, Fusion Energy 2012 (Proc. $24^{\text {rd }}$ IAEA Conf., San Diego, 2012) IAEA Vienna

E-mail: Peter.de.Vries@jet.efda.org

\begin{abstract}
In order to preserve the integrity of large tokamaks such as ITER, the number of disruptions has to be limited. JET has operated previously with a low frequency of disruptions (i.e. disruption rate) of 3.4\% [P.C. de Vries, et al., Nucl. Fusion 51 (2011) 053018]. The start of operations with the new full-metal ITER-like wall at JET showed a marked rise in the disruption rate to $10 \%$. A full survey was carried out to identify the root causes, the chain-of-events and classifying each disruption, similar to a previous analysis for carbonwall operations. It showed the improvements made to avoid various disruption classes, but also indicated those disruption types responsible for the enhanced disruption rate. The latter can be mainly attributed to disruptions due to too high core radiation but also due to density control issues and error field locked modes. Detailed technical and physics understanding of disruption causes is essential for devising optimized strategies to avoid or mitigate these events.
\end{abstract}




\section{Introduction}

During a disruption the growth of instabilities destroy the confinement, yielding a rapid loss of a large fraction of the thermal energy (i.e. the thermal quench). This usually leads to a plasma current quench on a slower time scale and is often accompanied by a loss of vertical stability, a so-call vertical displacement event (VDE) [1,2]. Disruptions are a key issue for large Tokamaks such as ITER because of the fast release of high thermal and magnetic energies, resulting in large electromagnetic forces and extreme heat loads that can compromise the integrity of the device [3,4]. At JET, presently the largest tokamak in the world, excessive disruption forces have caused damage to in-vessel components in the past. Moreover, the recent installation of the new, part Beryllium and part Tungsten, ITER-like wall (ILW) [5] has made the plasmafacing components less tolerable to heat loads and disruptions were found to be capable of causing localised melting of Beryllium PFCs [6]. This is exacerbated by the fact that the change in main chamber plasmafacing-components (PFCs) from carbon to Beryllium has resulted in significantly less energy being radiated during the disruption process. Hence, during a disruption a larger fraction of the plasma thermal and magnetic energy is conducted to the already more fragile ILW. With the carbon wall the post thermal quench temperature was held low by impurity line radiation [7]. With the ILW, the lower radiation allowed higher plasma temperatures during the current quench, thus slowing it down because it scales inversely with the plasma resistivity. The slower current quench made it more difficult to generate runaway electrons at JET, but also resulted in larger vessel displacements due to resonant amplification $[8,9]$. These results made it necessary to start using active mitigation by means of massive gas injection (MGI), for operations at higher plasma current $\left(\mathrm{I}_{\mathrm{p}} \geq 2.5 \mathrm{MA}\right)$, in order to safely operate with the ILW [10,9].

It is clear that disruptive events should, at best, be avoided. A figure-of-merit for disruption avoidance is the disruption rate, i.e. the fraction of discharges that disrupt unintentionally [11]. JET has operated during the last years with carbon PFCs with a relatively low disruption rate of 3.4\% [12]. The start of operations with the ILW in 2011/2012 showed a marked rise in the average disruption rate to $10 \%$ [8]. Such an increase could be expected temporarily, as the impact of the ILW on plasma behaviour will require tuning and redevelopment of operation scenarios and control schemes that were established during carbon wall operations. The trends in disruption rates observed during first operations with the ILW are summarised in section II and compared with previous carbon wall operation.

Disruptions are usually caused by a complex sequence of events that eventually push the tokamak plasma towards its stability limits. The reasons for the more frequent disruptions (i.e. higher disruption rate) can only be understood if a clear picture of the exact causes of each ILW disruption is obtained. This means on the one hand an analysis of technical issues, often control problems, but also a detailed look into the physics instabilities that develop in these discharges. Section III will present an overview of this analysis, high-lighting the differences seen between operation prior and post ILW installation. Effective disruption avoidance and prediction schemes can only be developed when detailed knowledge of the root causes and subsequent events leading up to a disruption are at hand. The dominant cause of disruptions during 2011- 
2012 ILW operation was found to be due to too high levels of high-Z impurities and high core radiation. Section IV gives a description of the development of such disruptions.

Only a full statistical analysis of the occurrence of this class of disruptions will provide quantitive information on the effectiveness of avoidance techniques and possible warning signs that could be used to trigger mitigating actions. For example the disruptivity [11] can be determined as a function of various plasma parameters and these results will be shown and discussed in section V. A new statistical analysis will be presented in section VI providing a better picture on why these slowly developing disruptions occur but also indicating possible warning signs and methods that can be used to avoid them. The final section VII will discuss the conclusions and provide an outlook to the future campaigns at JET.

\section{Disruption avoidance with the ITER-like wall}

During the first operations with the ILW in 2011 to 2012 in total 400 disruptions took place, of which 126 were intentionally performed to study disruption physics, yielding 274 unintentional disruptions. It is important to note that disruptions are counted here as those events having a current quench faster than $\mathrm{dI}_{\mathrm{p}} / \mathrm{dt}>5 \mathrm{MA} / \mathrm{s}$ that start at a plasma current $\mathrm{I}_{\mathrm{p}}>1 \mathrm{MA}$. As will be shown in section IV, the exact definition is especially important for the accounting of ILW disruptions. The ILW can affect the disruption physics such that it slows down the current quench [8], in some cases, to such an extent that a thermal quench is observed without being followed by a significant current quench at all.

The disruption rate is defined as the fraction of plasma discharges with a plasma current above $\mathrm{I}_{\mathrm{p}}=1 \mathrm{MA}$ that have unintentional disruptions at or above this current [11]. In total 2824 discharges with a plasma current above $\mathrm{I}_{\mathrm{p}}>1 \mathrm{MA}$ were carried out in 2011-2012, yielding an averaged unintentional disruption rate of $10 \%$. It is however important to understand that the JET tokamak is an experiment, meaning it develops new scenarios and actively explores its stability boundaries, which will negatively impact on the disruption avoidance. Nevertheless, this unintentional disruption rate is higher than that achieved during last experimental campaigns carried out with the carbon wall, which was as low as $3.4 \%$ [12].

These values are averaged over a large period of operation and usually large variations are found. In figure 1 the disruption rate for the various stages of the campaign to explore and expand operations with the ILW is shown. The campaign started with a series of short interleaved commissioning and experimental phases (pulse range 80128-81725) during which the operation range, especially of the auxiliary power, was enhanced. More exploration was done during the experimental phases which showed a slightly higher disruption rate than during pure commissioning. However, during these moderate power phases the overall rate was rather limited and well below 10\%. Thereafter H-mode operations started (81725-83620), yielding an increase in the number of disruptions with eventually a period of high current and high auxiliary power experiments during which $20 \%$ of all discharges disrupted. However, the campaigns were ended with 2 weeks of repetitive operations of a well-prepared H-mode scenario (83621-83794). Of the 152 nearly 
identical plasma discharges only $5(3.3 \%)$ disrupted, suggesting that absence of experimentation and exploration can avoid disruptions but also that ILW operation with a low disruption rate is possible.

\section{Disruption causes with the ITER-like wall}

The start of operations with the new ILW has shown to have affected JET operations in many ways [13]. The need for redevelopment of operating scenarios and control schemes, that were well-established for the carbon wall, can explain the observed increase in disruption rate. To obtain a better insight however, technical and physics causes of disruptions need to be analysed. For each of the 275 unintentional disruptions, that occurred during ILW operations in 2011-2012, the sequence of events that led to the thermal quench has been determined. The methods used were identical to those employed for the survey of carbon wall disruptions [12]. Figure 2 shows a statistical summary of the results for the ILW which can be directly compared to the equivalent carbon wall study as shown in figure 4 of ref. [12], although this concerned data from a much longer operational period. Table 1, explains the labelling of each node, identified as a characteristic problem or step in the process that eventually results in a disruption.

Those disruptions that follow a typical path through figure 2 can be grouped or classed together as was previously done for carbon wall operation [12]. In table 2, the occurrence of the various disruption classes as fraction of the number of discharges (with $\mathrm{I}_{\mathrm{p}}>1 \mathrm{MA}$ ) for 3 operational periods is given. The data are shown for a long period of carbon wall operation from 2000 to 2010 used in ref. [12]. This first series is an average over nearly a decade of operations. A better comparison is between the two periods directly before the installation of the ILW (2007 to 2009) and after (2011 to 2012), given in the last two columns of table 2 , respectively.

There are a number of obvious differences. For example no disruptions due to too strong internal transport barriers (ITB) took place, for the simple reason that ITB scenarios were not performed yet with the ILW so far. The absence of any disruptions due to vertical stability (VS) control issues might be attributable to the VS control upgrade prior to the installation of the ILW [14]. Moreover, advancement in the design of emergency termination scenarios seems to have improved the control over the plasma during such events and avoided disruptions, shown by the absence of a return-path ML $\rightarrow$ STOP (indicated by the dashed line in figure 1). This was a frequent problem during carbon wall operations [12].

It was observed experimentally, that higher line-averaged densities could be achieved in H-mode with the ILW compared with a carbon wall $[15,8]$. The explanation for this change in density-limit can be found in the lower carbon levels, hence lower radiation levels and different recycling properties, when operating at high densities with the ILW. However, similar as for carbon wall operations, very few unintentional H-mode density limit disruptions usually occur, [12]. Thus little beneficial effect on the occurrence of disruptions can be attributed to the change in the H-mode density limit. Although often intentionally studied, natural Greenwald limit disruptions do not feature regularly during normal operations, as shown in table 2. More common for operations with a carbon wall was that density control was 
compromised by increased recycling when errors in the position or shape control brought the plasma too close to the carbon wall, following the path $\mathrm{SC} \rightarrow \mathrm{WAL} \rightarrow \mathrm{RCY}$. The change in recycling properties with the new ILW meant that only very few such disruptions occurred as can be seen in figure 2 . The occurrence of other disruption classes, such as for example neo-classical tearing modes (NTMs) was found to be unchanged.

Besides these positive differences, some paths have worsened in 2011-2012. Firstly, it was found that more often disruptions due to error field locked modes took place. The new wall is rather uncompromising with respect to any failure of density control. In case of a failed actuator (gas valve) or erroneous control signal, the density may drop quickly to very low levels. This in turn will allow error field locked modes to penetrate the plasma $(\mathrm{NC} \rightarrow \mathrm{LON} \rightarrow \mathrm{ML})$, while with the carbon wall, recycling often maintained a high enough density to avoid these modes. Secondly, disruptions occurred due to strong radiation peaking, something that was uncommon (but not absent) with the carbon wall, which were grouped in a new class in table 2. Such problems occurred in 4.6\% of all discharges in 2011-2012, making it, by far, the dominant disruption cause. In total 131 cases were identified and if these would have been avoided the disruption rate would have been a respectable $5 \%$.

Of these 131 cases 52\% happened during the exit from H-mode (after the switch-off of the auxiliary heating), although usually the radiation peaking already developed during the main heating phase. It should be said that analysis presented here does not give a clear root cause for this disruption class. That is, the reasons for the strong core impurity radiation are not always clear. Often the radiation peaking is a slow process, associated to high $\mathrm{Z}$ impurity transport yielding impurity accumulation in the core. Although in $30 \%$ of the cases the radiation increase is much faster than transport time-scales and might be associated by a sudden in-flux of impurity material due to an enhanced divertor source. Such fast influxes should not be confused by events caused by so-called UFOs or transient impurity events. Although such events were often found to be present in ILW discharges [16], fewer caused disruptions, compared to carbon wall operations in 2007 to 2009 [12].

\section{Disruptions due to high core radiation}

This section describes the plasma destabilization due to radiation peaking that resulted in disruptions of nearly $\sim 15 \%$ of all H-mode pulses during 2011-2012. In figure 3, a typical example is shown of a discharge that accumulates high $\mathrm{Z}$ impurities and develops a strongly peaked radiation profile. In this specific case the radiation increases rapidly, after about $\mathrm{t} \sim 10.5 \mathrm{~s}$, associated with a sudden increase of the divertor impurity source. Although the total radiation never exceeds the total input power, locally in the core it affects the power balance and within $\sim 500 \mathrm{~ms}$ the temperature profile becomes hollow while the density profile strongly peaks. Thereafter these profiles stabilise.

On a much slower (resistive) time scale, the hollow temperature profile, starts to affect the current density, indicated by the slow reduction in internal inductance. CRONOS interpretative calculations [17] 
provide information on the q-profile modification, showing the slow development of a hollow q-profile with a central $\mathrm{q}$ reaching $\mathrm{q}_{\mathrm{o}}>2$ at $\mathrm{t} \sim 12.7 \mathrm{~s}$. This is corroborated by the frequencies of various MHD instabilities spinning up (figure 4), suggesting rational q-surfaces moving inward. These core instabilities and the value of $\mathrm{q}_{\mathrm{o}}$ are not the reason for the disruption and in other examples a much smaller increase of $\mathrm{q}_{\mathrm{o}}$ is found. These disruptions are always initiated by a low frequency, here $\mathrm{f} \sim 2.5 \mathrm{kHz}, \mathrm{n}=1$ instability (figure 4 ) in the outer part of the plasma [18]. As shown in figure 4, this mode can remain in the plasma for more than a second, although there are also cases seen that lock immediately. In figure 3 the mode shows a sudden growth from $\mathrm{t}=12.8 \mathrm{~s}$, when it locks, growing further, yielding a first thermal quench at $\mathrm{t}=13.16 \mathrm{~s}$. It is thought, but not proven, that this mode is driven unstable by the broadening of the q-profile, due to current being expelled from the cold core. It suggests a relation to similar instabilities found during too fast current ramp-ups or in advanced tokamak scenarios when the edge $\mathrm{q}$ is close to a rational value [12]. Hence, a fast reduction of the plasma current may have a stabilizing effect on these plasmas. Note the particularly slow current quench that follows the first thermal quench, lasting for nearly a second, until finally just before $\mathrm{t}=14 \mathrm{~s}$ a VDE develops, which increases the current quench rate.

This class of disruptions develops slowly, on resistive timescales allowing the change in q-profile required to trigger the MHD instabilities, and hence provide ample warning signs for the triggering of mitigating schemes. One should note that the features described above are more common than the occurrence of disruptions (i.e. a fast current quench). The thermal quench of the actual disruption process, might have a beneficial impact on the plasma, by ejecting part of the high- $Z$ material from the core. Hence, after the thermal quench the (core) temperature could increase significantly with the ILW, preventing a clear current quench and often yielding a soft landing [8]. A comparison of two identical discharges is shown in figure 5 , with marked drops in radiation after the thermal quench followed by an increase in the core temperature. One case results in a soft landing while the other loses shape and vertical stability control, yielding a VDE. With the carbon wall, predominantly carbon radiation would have kept the post-thermal quench temperature low, preventing the temperature increase by Ohmic heating, the healing of flux surfaces and always ensuring a fast current quench.

Approximately $35 \%$ of all $\mathrm{H}$-mode discharges with the ILW developed a thermal quench, though less than half developed a current quench fast enough to be counted as a disruption according to the definition used in section II. The fact that current quenches are significantly slower or even absent with the ILW makes disruption accounting more ambiguous compared to carbon wall operations and affects the calculation of the disruption rate and disruptivity, as will be shown in the next section. Obviously this will also complicate the assessment of disruption predictors that usually aim to detect the thermal quench [19]. The cause analysis presented in section II is done only up to first thermal quench. For the ILW the period after the first thermal quench can have a significant duration, during which new instabilities may grow triggering further thermal quenches, or plasma stability might be compromised in other ways, like the development of a VDE. 


\section{Disruptivity with the ITER-like wall}

A statistical analysis of the occurrence of disruption classes, such as discussed in the previous section, with respect to the operational range, can provide useful information on why and when such disruptions may develop. The disruptivity is the likelihood that tokamak plasmas within a specific operational state, disrupts. It can be defined as the number of times a disruption occurs when the plasma is within a specific parameter range, divided by the total duration the device operated within the same range [11]. It is worth recalling that a disruption is here defined by the development of a fast current quench.

As pointed out above, whether a fast current quench would develop after the thermal quench, or not, may depend on the post-quench stability. Figure 6a shows the disruptivity over the period 2011-2012 as a function of plasma triangularity. A higher disruptivity is found for high triangularity configurations, because these usually have a faster vertical growth rate and hence are more difficult to control and prone to develop a VDE and thus a fast current quench. Redundancy in control systems, in this case the vertical stability control, clearly affects the disruptivity. The two discharges compared in figure 5 both used a low triangularity configuration, increasing the likelihood that the vertical stability after the thermal quench can be maintained. The class of disruptions shown in figure 5, also shows a strong degradation of energy confinement prior to the thermal quench. Hence, the associated $\beta$ drop is limited avoiding further difficulties for the vertical position control.

Another factor that determines disruptivity can be related to the mitigating action triggered by precursors or the thermal quench itself. At plasma currents of $\mathrm{I}_{\mathrm{p}} \geq 2.5 \mathrm{MA}$, ILW operation required the active mitigation by MGI that was usually triggered by the locked mode at the thermal quench [10], hence, enforcing fast current quench. The pre-emptive use of MGI therefore resulted in a higher disruptivity when operating at higher plasma currents as shown in figure $6 \mathrm{~b}$ and increased the overall disruption rate during the latter part of the 2012 campaign (see figure 1).

Although the disruption rate gives a general figure-of-merit for disruption avoidance, the disruptivity can provide information on those physics parameters that determine the plasma stability or disruptive operational limits $[11,20]$. Note that the average disruptivity, over the entire operational space and period, is equal to the average disruption rate divided by the average pulse duration. Thus the average level may vary per operational period. But above average disruptivity for a specific operational range indicates that likelihood to develop a disruption has increased. Disruptivity calculations can be used to obtain insight in what the key parameters are that determine the occurrence of the new disruption class, discussed in section IV. Moreover, it may provide information on how to avoid such disruptions.

However there are a number of deficiencies with respect to the definition of disruptivity, as given above, which would complicate such study. Firstly, the definition above is an all inclusive calculation, 
meaning that different disruption classes are added together. This is fine when studying the disruptivity with respect to operational parameters or the proximity to main operational limits $[11,20]$, however for a better physics insight on one type of disruption, it might be better not to mix the data of different disruption classes. Secondly, the disruptivity assumes a direct causality between the present plasma state and the occurrence of a disruption. In reality the disruption process may develop slowly and the disruption may occur when the plasma has changed state, compared to that when the instabilities are triggered that eventually lead to the disruption. For example, disruptions that reach the H-mode density limit usually result into a back-transition to a lower confinement and density state in which the disruption takes place. Hence, it doesn't disrupt exactly at the density limit. Similarly, as shown in section IV, the disruptions due to high-Z impurities and core radiation, develop slowly, with significant delays between the modification of key plasma parameters, i.e. the temperature and q profiles, the triggering of the MHD instability and its final locking and disruption. The time-delayed causality that exists for many disruptive processes will blur the image obtained when calculating the standard disruptivity as defined previously [11]. In reality the plasma stability and disruptivity will depend on multiple parameters and resolving these complex correlations requires more advanced multi-dimensional studies such as reported in refs. [21, 22]. Finally, disruption classes are characterized by the chain of events that lead to the thermal quench, which may be disconnected from the development of the current quench, as discussed above. Hence, if one would like to use calculations of disruptivity to study specific disruption classes, one should link it to the occurrence of the event of the thermal quench.

In order not to mix different disruptive processes, the disruptivity has been calculated over all discharges in 2011-2012 that either did not disrupt or disrupted due to high radiation peaking. Discharges that developed other disruption classes were filtered out. Parameters were sampled every $50 \mathrm{~ms}$ providing 104585 data points per parameter, totalling 1.453 hours of plasma operations. All cases that developed a thermal quench have been regarded as disruptive, in total 228 cases which is $33.8 \%$ of the total. This is a higher percentage than would be obtained if only fast current quenches are considered. The average disruptivity over the entire dataset is $4310^{-3} \mathrm{~s}^{-1}$.

In figure $7 \mathrm{a}$, the disruptivity is shown as a function of the peaking of both the radiation and temperature profile. These parameters are calculated, respectively, as the ratio of the sum of two central channels (\#13,\#15) and the sum of two off-axis channels (\#10,\#20) of the horizontal bolometer and the ratio of the core electron temperature and that in the outer part of the plasma $(\mathrm{r} / \mathrm{a}=0.6)$, as measured by HighResolution Thomson Scattering (HRTS). The figure shows that with higher values of radiation profile peaking, flatter or hollow temperature profiles are obtained. Areas with very high disruptivity $\left(>1 \mathrm{~s}^{-1}\right)$ are found in parameter ranges with flat or hollow temperature profiles. But a clear disruptive limit is difficult to draw in figure $7 \mathrm{a}$.

\section{Predictive disruptivity}


To take into consideration the time-delayed causality, a new calculation has been performed. The time that all discharges, that will eventually disrupt, were within a specific parameter space, is divided by the total duration (disruptive and non-disruptive) operated in the same range. This ratio is labelled the 'predictive disruptivity'. While the disruptivity gives the likelihood of a disruption within a specific parameter space, the predictive disruptivity indicates if it may disrupt later when it moves through this space. A value of unity means that all discharges that reached this parameter range will disrupt, although not necessarily at this point. The predictive disruptivity shown in figure $7 \mathrm{~b}$, can be compared with figure $7 \mathrm{a}$, and shows a clear area in which disruptions due to radiation peaking are unavoidable. All disruptions due to high core radiation in 2011-2012 were found to be in this area at one point of time.

In this dataset $33.8 \%$ of all discharges disrupted (i.e. developed a thermal quench), and any areas with a predictive disruptivity less than this value can be regarded as particularly safe. Not only is this operational space less disruptive but it is also less likely develop towards a more unstable area. Hence, operation in this area may avoid disruptions all together. This shows that predictive disruptivity can form a strong basis for both the development of avoidance techniques and triggers for mitigation schemes. One can determine the average time it takes before a disruption takes place, as shown in figure $7 \mathrm{c}$. In the area where disruptions are unavoidable still an averaged time-to-disruption of roughly a second is found. Interestingly contours of constant time-to-disruption show a vertical pattern, suggesting that this time is less dependent on the shape of the temperature profile. However, the predictive disruptivity, in figure $7 \mathrm{~b}$, clearly shows a dependence on both the radiation and temperature profile shape.

The parameters used in figure 7 are obviously relevant to this specific disruption class. Trends with other parameters are less clear, and the occurrence of these disruptions seemed not to be connected to, for example; total amount of radiation ot edge temperatures. The same counts for operational parameters like the plasma current, total input power and the amount of gas dosing during the H-mode phase, used to control the impurity source. More likely linked to the MHD destabilization, than the temperature profile peaking, is the shape of the q-profile itself, which is however, not easily obtained for the large dataset used here. Figure 8 shows disruptivity and predictive disruptivity as a function of the safety factor at the edge $\left(\mathrm{q}_{95}\right)$ and the internal inductance. The figure shows that there is a relationship between lower inductance, i.e. broader q-profiles, and the occurrence of this class of disruptions. Moreover, the likelihood increases significantly when operating below $\mathrm{q}_{95}=4$. Although with the ITER-like wall impurity accumulation issues are just as problematic in hybrid scenarios (at $\mathrm{q}_{95} \sim 4$ ) compared to baseline operation (at $\mathrm{q}_{95} \sim 3$ ), disruptions as a consequence of the impurity influx are less likely. Furthermore, the inset in figure $8 \mathrm{~b}$ suggests a correlation between these disruptions and the proximity of edge rational q (i.e. q95 2,3 and 4). This is further indication about the MHD that is destabilized by the processes described in section IV, although as always with statistical studies correlation does not necessarily implies causation.

It is well-known that providing central electron heating counter acts inward transport of high-Z impurities [23, 24, 25]. Providing central heating and keeping temperature profiles peaked is obviously a 
clear strategy to avoid these disruptions. In figure 9 the predictive disruptivity is shown as a function of the fraction of the Ion Cyclotron Resonance Heating (ICRH) power to the total input power ( $f_{\text {ICRH }}$ ) and again the temperature profile peaking. ICRH is the only heating scheme at JET that can provide significant localised on-axis electron heating, while neutral beam injection (NBI), especially at high density, has a rather broad power deposition profile. Because the ICRH power during the 2011-2012 operational period was limited, the dataset used to calculate the predictive disruptivity in figure 9, was enlarged by also including data from the first period of operations in 2013. During the latter period up to $\mathrm{P}_{\text {ICRH}}=7 \mathrm{MW}$ was coupled in H-mode discharges. Note that these statistics are done only for the class of disruptions related to impurity accumulation. Figure 9 shows a number of interesting features. Firstly, that flat or hollow temperature profiles did not develop with $\mathrm{f}_{\mathrm{ICRH}}>0.5$. Secondly, for a constant temperature profile peaking factor (between 3 and 5) the predictive disruptivity decreases with ICRH power fraction. Operating without ICRH shows a disruption probability $>30 \%$, being the average of the considered period of operations. This reduces by a third to below $20 \%$ for $0.1<\mathrm{f}_{\mathrm{ICRH}}<0.2$ and by two thirds to below $10 \%$ if $\mathrm{f}_{\text {ICRH }}>0.3$.

\section{Discussion and outlook}

The ILW reduced the amount of energy radiated during JET disruptions, yielding larger amounts of energy being conducted to the mainly beryllium first wall and moreover, larger forces on the vessel $[8,9]$. MGI can be applied to ensure higher radiation, mitigating the impact of disruptions. Usually much effort is devoted to improving the detection of disruptions, to ensure the timely application of such drastic mitigation techniques as MGI. However, for most disruption classes there are ample warning signs, visible well before the thermal quench. More difficult than timely detection is, to develop a set of measures that would either prevent further development of the problem (i.e. disruption avoidance) or create a soft landing (i.e. reducing plasma current and energy on time). A full statistical study on the occurrence of various disruption causes, for example by calculating the disruptivity, gives key information on how to detect and avoid them. It provides a quantification of the detection effectiveness or efficiency of avoidance methods.

Disruptions were more frequent during the first operations with the new ILW compared to recent carbon-wall operation, with an average disruption rate of $10 \%$ for 2011-2012. The increase can be explained by the impact of the ILW on plasma behaviour requiring tuning and redevelopment of standard operation scenarios and control schemes. For example the ILW altered the density control hence, scenarios and density control recipes, tuned during $\mathrm{C}$ wall operations, which had to be redeveloped. The reduction in wall recycling led several times to too low a density and hence error field locked modes. Independent from the ILW, it was found that the implementation of better controlled emergency terminations, avoided disruptions that previously often took place when trying to shut-down the plasma.

An all-inclusive statistical analysis of disruptive events is not only important to build an honest picture of disruption avoidance, but also provide valuable information on disruption detection/prediction and even the underlying physics of disruption. It should be noted that disruption accounting and thus the 
calculation of the disruption rate, is complicated by the ambiguity of the disruption process with the ILW. It depends on the exact definition of a disruptive event. For JET a fast current quench and VDE is the most relevant event as this phase results in the largest forces and heat loads. Although a fast thermal quench alone might already lead to excessive power loads on the first wall in larger and hotter devices such as ITER.

With the ILW, a current quench is not necessarily the consequence of the thermal quench. Hence cause of the current quench is therefore (partly) disconnected from the sequence of events that leads to the thermal quench. Although the thermal quench could be predicted using the typical warning signs that can be observed during the events that lead up to it, these same precursors may not determine whether a fast current quench develops, i.e. if the plasma disrupts. The disruptivity was therefore also found to be dependent on the plasma stability after the thermal quench, rather than prior to it. Pre-emptive use of MGI, normally triggered by the thermal quench or its precursors, increased the number of disruptions as not all thermal quenches would always result in a real disruption. Operating without an active MGI mitigation system would have resulted in a lower disruption rate, although with the significant risk of melt damage at any unmitigated disruption.

The predominant disruption cause during the first period of operations with the ILW was high core radiation due to high- $Z$ impurities. In order to avoid these disruptions, and reduce the disruption rate, proper detection and mitigation strategies are being developed. MHD instabilities are triggered by the broadening of the current density profile, as more current is expelled from the core due to the low temperatures. The calculation of the predictive disruptivity shows a correlation with discrete values of $\mathrm{q}_{95}$, suggesting this plays a role in either the triggering of these MHD instabilities or their final locking and growth that leads to the thermal quench. The development of these disruptions is usually slow (i.e. order of the resistive time), hence ignoring the dynamics may complicate the study to correlate specific parameters (ranges) to the occurrence of these disruptions. This is better achieved using the calculation of the predictive disruptivity which determines not only if a plasma disrupts but also that it may do so lateron. The predictive disruptivity for these disruptions was found to strongly depend on the hollowness of the temperature profile and the peaking of the radiation profile. These two parameters define an area in which these disruptions are unavoidable, albeit still with a warning time of approximately 1 second. The root cause of this class of disruptions is not (yet) clearly determined. Those cases caused by a fast influx of material might suggest improvement of impurity source control. However, most showed signs of slow accumulation. Hence, it is imperative to control high-Z impurity transport in JET discharges [25].

It was shown that the occurrence of these disruptions can be reduced by the application of significant fractions of ICRH, an important scheme that will help to reduce the disruption rate in further JET campaigns. Note that the 2012 campaigns were finalised by 2 weeks of repetitive H-mode operations, with a disruption rate of only 3.3\%. Presently JET is expanding its operational range with the ILW, increasing the auxiliary heating power $(>30 \mathrm{MW})$, at higher plasma currents $\left(\mathrm{I}_{\mathrm{p}}>3.5 \mathrm{MA}\right)$, in preparation for 
possible future D-T experiments [26]. Such an experimental development is expected to lead to more disruptions, but is also part of the learning process, eventually reducing the disruption rate to levels acceptable for safe operation at high current.

\section{Acknowledgements}

This research was funded partly by the European Communities under the contract of Association between EURATOM and FOM. This work was carried out within the framework of the European Fusion Development Agreement. The views and opinions expressed herein do not necessarily reflect those of the European Commission. 


\section{References}

[1] J.A. Wesson, R.D. Gill, M. Hugon, F.C. Schüller, J.A. Snipes, D.J. Ward, D.V. Bartlett, D.J. Campbell, P.A. Duperrex, A.W. Edwards, R.S. Granetz, N.A.O. Gottardi, T.C. Hender, E. Lazzaro, P.J. Lomas, N. Lopes Cardozo, K.F. Mast, M.F.F. Nave, N.A. Salmon, P. Smeulders, P.R. Thomas, B.J.D. Tubbing, M.F. Turner $^{1}$ and A. Weller, Nucl. Fusion 29 (1989) 641.

[2] F.C. Schüller, Plasma Phys. Control. Fusion 37 (1995) A135.

[3] M. Sugihara, M. Shimada, H. Fujieda, Yu. Gribov, K. Ioki, Y. Kawano, R. Khayrutdinov, V. Lukash and J. Ohmori, Nucl. Fusion 47 (2007) 337.

[4] T.C. Hender, J.C Wesley, J. Bialek, A. Bondeson, A.H. Boozer, R.J. Buttery, A. Garofalo, T.P Goodman, R.S. Granetz, Y. Gribov, O. Gruber, M. Gryaznevich, G. Giruzzi, S. Günter, N. Hayashi, P. Helander, C.C. Hegna, D.F. Howel, D.A. Humphreys, G.T.A. Huysmans, A.W. Hyatt, A. Isayama, S.C. Jardin, Y. Kawano, A. Kellman, C. Kessel, H.R. Koslowski, R.J. La Haye, E. Lazzaro, Y.Q. Liu, V. Lukash, J. Manickam, S. Medvedev, V. Mertens, S.V. Mirnov, Y. Nakamura, G. Navratil, M. Okabayashi, T. Ozeki, R. Paccagnella, G. Pautasso, F. Porcelli, V.D. Pustovitov, V. Riccardo, M. Sato, O. Sauter, M.J. Schaffer, M. Shimada, P. Sonato, E.J. Strait, M. Sugihara, M. Takechi, A.D. Turnbull2, E. Westerhof, D.G. Whyte, R. Yoshino, H. Zohm and the ITPA MHD, Disruption and Magnetic Control Topical Group, Nucl. Fusion 47 (2007) S128.

[5] G.F. Matthews, M. Beurskens, S. Brezinsek, M. Groth, E. Joffrin, A. Loving, M. Kear, M-L. Mayoral, R. Neu, P. Prior, V. Riccardo, F. Rimini, M. Rubel, G. Sips, E. Villedieu, P. de Vries, M.L. Watkins and EFDA-JET contributors, Phys. Scripta T128 (2011) 014001.

[6] M. Lehnen, G. Arnoux, N. Hartmann, S Brezinsek, S. Devaux, A. Huber, S. Jachmich, U. Kruezi, G.F. Matthews, C. Reux, V. Riccardo, B. Sieglin, M.F. Stamp, P.C. de Vries and JET EFDA Contributors, Journ. Nucl. Mat. 438 (2013) S102.

[7] D.J. Ward and J.A. Wesson, Nucl. Fusion (1992) 1117.

[8] P.C. de Vries, G. Arnoux, A. Huber, J. Flanagan, M. Lehnen, V. Riccardo, C. Reux, S. Jachmich, C. Lowry, G. Calabro, D. Frigione, M. Tsalas, N. Hartmann, S. Brezinsek, M. Clever, D. Douai, M. Groth, T. C. Hender, E. Hodille, E. Joffrin, U. Kruezi, G. F. Matthews, J. Morris, R. Neu, V. Philipps, G. Sergienko, M. Sertoli, and JET-EFDA Contributors, Plasma Phys. Control. Fusion 54 (2012) 124032. 
[9] M. Lehnen, G. Arnoux, S. Brezinsek, J. Flanagan, S.N. Gerasimov, N. Hartmann, T.C. Hender, A. Huber, S. Jachmich, V. Kiptily, U. Kruezi, G.F. Matthews, J. Morris, V.V. Plyusnin, C. Reux, V. Riccardo, B. Sieglin, P.C. de Vries and JET EFDA Contributors, Nucl. Fusion 53 (2013) 093007.

[10] C. Reux, M. Lehnen, U. Kruezi, S. Jachmich, P. Card, K. Heinola, E. Joffrin, P.J. Lomas, S. Marsen, G. Matthews, V. Riccardo, F. Rimini, P. de Vries, JET EFDA Contributors, Fus. Eng. Des. 88 (2013) 1101. http://dx.doi.org/10.1016/j.fusengdes.2012.12.026

[11] P.C. de Vries, M.F. Johnson, I. Segui and JET EFDA Contributors, Nucl. Fusion 49 (2009) 055011.

[12] P.C. de Vries, M.F. Johnson, B. Alper, P. Buratti, T.C. Hender, H.R. Koslowski, V. Riccardo and JETEFDA Contributors, Nucl. Fusion 51 (2011) 053018.

[13] R. Neu, G. Arnoux, M. Beurskens, V. Bobkov, S. Brezinsek, J. Bucalossi G. Calabro, C. Challis, J. W. Coenen, E. de la Luna, P. C. de Vries, R. Dux, L. Frassinetti, C. Giroud, M. Groth, J. Hobirk, E. Joffrin, P. Lang, M. Lehnen, E. Lerche, T. Loarer, P. Lomas, G. Maddison, C. Maggi, G. Matthews, S. Marsen, M.-L. Mayoral, A. Meigs, Ph. Mertens, I. Nunes, V. Philipps, T. Pütterich, F. Rimini, M. Sertoli, B. Sieglin, A. C. C. Sips, D. van Eester, G. van Rooij, and JET-EFDA Contributors, Phys. Plasmas 20, 056111 (2013).

[14] F.G. Rimini, F. Crisanti, Raffaele Albanese, G. Ambrosino, M. Ariola, G. Artaserse, T. Bellizio, e, V. Coccorese, G. De Tommasi, P. de Vries, P.J. Lomas, F. Maviglia, A. Neto, Isabel Nunes, A. Pironti, G. Ramogidaa, F. Sartoria, S.R. Shawa, Maximos Tsalas, R. Vitelli, L. Zabeo, JET EFDA Contributors, Fusion Eng. Des. 86 (2011) 539.

[15] A. Huber, S. Brezinsek, M. Groth, P.C. de Vries, V. Riccardo, G. van Rooij, G. Sergienko, G. Arnoux, A. Boboc, P. Bilkova, G. Calabro, M. Clever, J.W. Coenen, M.N.A. Beurskens, T. Eich, S. Jachmich,, M. Lehnen, E. Lerche, S. Marsen, G.F. Matthew, K. McCormick, A.G. Meigs, Ph. Mertens, V. Philipps, J. Rapp, U. Samm, M. Stamp, M. Wischmeier, S. Wiesen, JET-EFDA contributors, Journ. Nucl. Mat. 438 (2013) S139.

[16] M.Sertoli, J.C. Flanagan, A. Cackett, E. Hodille, P. de Vries, I.H. Coffey, B. Sieglin, S. Marsen, S. Brezinsek, G.F. Matthews, J.W. Coenen and JET-EFDA Contributors, Transient impurity events in JET with the new ITER-like wall and their impact on plasma operation, Phys. Scripta (2014) accepted.

[17] J.F. Artaud, V. Basiuk, F. Imbeaux, M. Schneider, J. Garcia, G. Giruzzi, P. Huynh, T. Aniel, F. Albajar, J.M. Ané, A. Bécoulet, C. Bourdelle, A. Casati, L. Colas, J. Decker, R. Dumont, L.G. Eriksson, X. 
Garbet, R. Guirlet, P. Hertout, G.T. Hoang, W. Houlberg, G. Huysmans, E. Joffrin, S.H. Kim, F. Köchl, J. Lister, X. Litaudon, P. Maget, R. Masset, B. Pégourié, Y. Peysson, P. Thomas, E. Tsitrone and F. Turco, Nucl.Fusion 50 (2010) 043001.

[18] M. Baruzzo, B. Alper, Yu.F. Baranov, T. Bolzonella, A Botrugno, C. Bourdelle, P. Buratti, R Coelho, C.D. Challis, I.T. Chapman, P.C. de Vries, D. Dodt, C. Giroud, M. Gelfusa, E. Joffrin, N. Hawkes, T.C. Hender, J. Hobirk, J. Mailloux, F. Orsitto, G. Pucella, SE. Sharapov, O. Tudisco, M. Valisa and JET-EFDA Contributors, ITER Like Wall impact on MHD instabilities in JET discharges, in Proc. $40^{\text {th }}$ of the EPS conference on Plasma Physics (Espoo, 2013), P5-161.

http://ocs.ciemat.es/EPS2013ABS/pdf/P5.161.pdf

[19] J. Vega, S. Dormido-Canto, J.M. López, A. Murari, J.M. Ramírez, R. Moreno, M. Ruiz, D. Alves, R. Felton, JET-EFDA Contributors, Fus. Eng. Des. 88 (2013) 1228.

http://dx.doi.org/10.1016/j.fusengdes.2013.03.003

[20] S.P. Gerhardt, R.E. Bell, A. Diallo, D. Gates, B.P. LeBlanc, J.E. Menard, D. Mueller, S.A. Sabbagh, V. Soukhanovskii, K. Tritz and H. Yuh, Nucl. Fusion 53 (2013) 043020.

[21] A. Murari, P. Boutot, J. Vega, M. Gelfusa, R. Moreno, G. Verdoolaege, P.C. de Vries and JET-EFDA Contributors, Nucl. Fusion 53 (2013) 033006.

[22] B. Cannas, A. Fanni, A. Murari, A. Pau, G. Sias and the JET EFDA Contributors, Plasma Phys. Control. Fusion 55 (2013) 045006.

[23] R. Dux, R. Neu, A.G. Peeters, G. Pereverzev, A. Mück, F. Ryter, J. Stober and ASDEX Upgrade Team, Plasma Phys. Control. Fusion 45 (2003) 1815.

[24] M. Valisa, L. Carraro, I. Predebon, M.E. Puiatti, C. Angioni, I. Coffey, C. Giroud, L. Lauro Taroni, B. Alper, M. Baruzzo, P. Belo daSilva, P. Buratti, L. Garzotti, D. Van Eester, E. Lerche, P. Mantica, V. Naulin, T. Tala, M. Tsalas and JET-EFDA contributors, Nucl. Fusion 51 (2011) 033002.

[25] T. Pütterich, R. Dux, R. Neu, M. Bernert, M.N.A. Beurskens, V. Bobkov, S. Brezinsek, C. Challis, J.W. Coenen, I. Coffey, A. Czarnecka, C. Giroud, P. Jacquet, E. Joffrin, A. Kallenbach, M. Lehnen, E. Lerche, E. de la Luna, S. Marsen, G. Matthews, M.-L. Mayoral, R.M. McDermott, A. Meigs, J. Mlynar, M. Sertoli, G. van Rooij, the ASDEX Upgrade Team and JET EFDA Contributors, Taming Tungsten in JET and ASDEX Upgrade, submitted to Plasma Phys. Controlled Fusion (2013). 
[26] A.C.C. Sips, C.D. Challis, H. Weisen, P. Batistoni, J. Bizarro, F. Crisanti, L-G Eriksson, J. Garcia, I. Jenkins, X. Litaudon, R. Neu, I. Nunes and JET EFDA Contributors, Scientific preparation for future D-T campaigns at JET in support of ITER, in Proc. of the $38^{\text {th }}$ EPS Conference on Plasma Physics (Strasbourg, 2011) O5-127, http://ocs.ciemat.es/EPS2011PAP/pdf/O5.127.pdf 


\section{Figure and table captions}

Figure 1: The unintentional and total disruption rate for the various stages of the first operations with the ILW at JET. The commissioning phases are labelled with a $\mathbf{c}$, additionally the fraction of discharges that had a disruption mitigated by massive gas injection is given.

Figure 2: A schematic overview, showing the statistics of the sequence-of-events up to the (first) thermal quench for 275 unintentional disruptions at JET during the period 2011 to 2012. The width of each arrow indicates the number of cases found in the database. For comparison with the carbon wall operations, the MHD $\rightarrow$ ML arrow width is kept the same as that used in figure 4 in ref. [12]. Table 1 and 2 explain the node labels. Those nodes in grey were absent in 2011-2012, while those in blue are new on the graph (RPK: radiation peaking, PRO: reciprocating probe, DIA: diagnostic failure)

Table 1: List of physics instabilities and limits or technical problems related to JET disruptions found during the period of 2000 to 2012, as explained in detail in ref. [12], with a new addition in italic, as discussed in section IV. The second column gives the label used in figure 2.

Table 2: Comparison of the occurrence of different JET disruption classes as a fraction of the number of discharges above $\mathrm{I}_{\mathrm{p}}=1 \mathrm{MA}$, i.e. $1 \%$ means, $1 \%$ of the discharges disrupted due to the specified class. The first column set gives the average over the period from 2000-2011, comprising 22243 discharges and 1654 disruptions as discussed in ref. [12]. The second column shows the data for the final carbon wall campaign from 2007 to 2009, having 6907 discharges and 364 disruptions, which can be compared directly with the third column that shows the average for the ILW campaign from 2011 to 2012 with 2824 discharges and 273 disruptions. For this campaign a new disruption class, due to too strong core radiation, has been added (in italic).

Figure 3: A summary of events of a characteristic disruption due to high- $Z$ impurity accumulation and a peaked radiation profile. a) The Plasma current. b) The total input and neutral beam injection (NBI) power only compared to the total radiative power. c) The core temperature and that at normalised radius of $\rho=0.7$ as measured by electron cyclotron emission (ECE) spectroscopy and high resolution Thomson scattering (HRTS). The (first) thermal quench is marked by an arrow. d) The volume averaged and central density as measured by HRTS. e) The amplitudes of $n=1$ and $n=2$ and the locked mode amplitudes. f) The internal inductance. 
Figure 4: Spectrogram summarising the $n=1,2,3$ and 4 MHD activity in the final stages of the JET pulse no. 82005 (see figure 3). The arrows give the times for which CRONOS calculated the central q to increase above the respective values.

Figure 5: Comparison of two nearly identical thermal quenches (marked by the arrows), one that develops a VDE and current quench while the other improves and results in a soft landing. a) The plasma current. b) The central temperature and that measured at 0.7 of the minor radius, as measured by the heterodyne Electron Cyclotron Emission (ECE) spectrometer. c) The total radiated power as measured by the JET bolometer. d) The radiation seen by JET bolometer channel, viewing horizontally through the plasma centre. e) The $n=1$ and locked mode amplitude shown by the dashed and solid curve, respectively. f) The vertical plasma position.

Figure 6: a) The disruptivity as a function of the triangularity, b) and as a function of plasma current, for all unintentional and mitigated disruptions in 2011-2012.

Figure 7: a) The disruptivity over 2011-2012 only considering disruptions due to high radiation peaking, as a function of the radiation and temperature profile peaking. b) The predictive disruptivity for the same parameter range. c) The average duration up to the thermal quench. In order to have statistical relevance only those parameter areas are shown for which at least $1.875 \mathrm{~s}$ of operation was achieved during 20112012 .

Figure 8: a) The disruptivity as a function of the edge safety factor $\left(\mathrm{q}_{95}\right)$ and the internal inductance using the same dataset as used for figure 7. b) The predictive disruptivity. The inset histogram gives the average values of predictive disruptivity versus $\mathrm{q}_{95}$ only, in arbitrary units.

Figure 9: a) The predictive disruptivity as function of the fraction of ICRH power, i.e. $f_{I C R H}=P_{\text {ICRH }} /$ $\left(\mathrm{P}_{\mathrm{ICRH}}+\mathrm{P}_{\mathrm{NBI}}+\mathrm{P}_{\mathrm{OHMIC}}\right)$, and the peaking of the temperature profile. The calculation was carried out using an extended dataset, comprising the same set as used for figure 7 and 8, enlarged with data from the first period of operation in 2013 (up to JET pulse no: 85335). b) A slice of the previous graph showing the average predictive disruptivity for a fixed range of temperature profile peaking (from 3 to 4 ) as a function of $f_{\text {ICRH. }}$. 


\section{Figures and Tables}

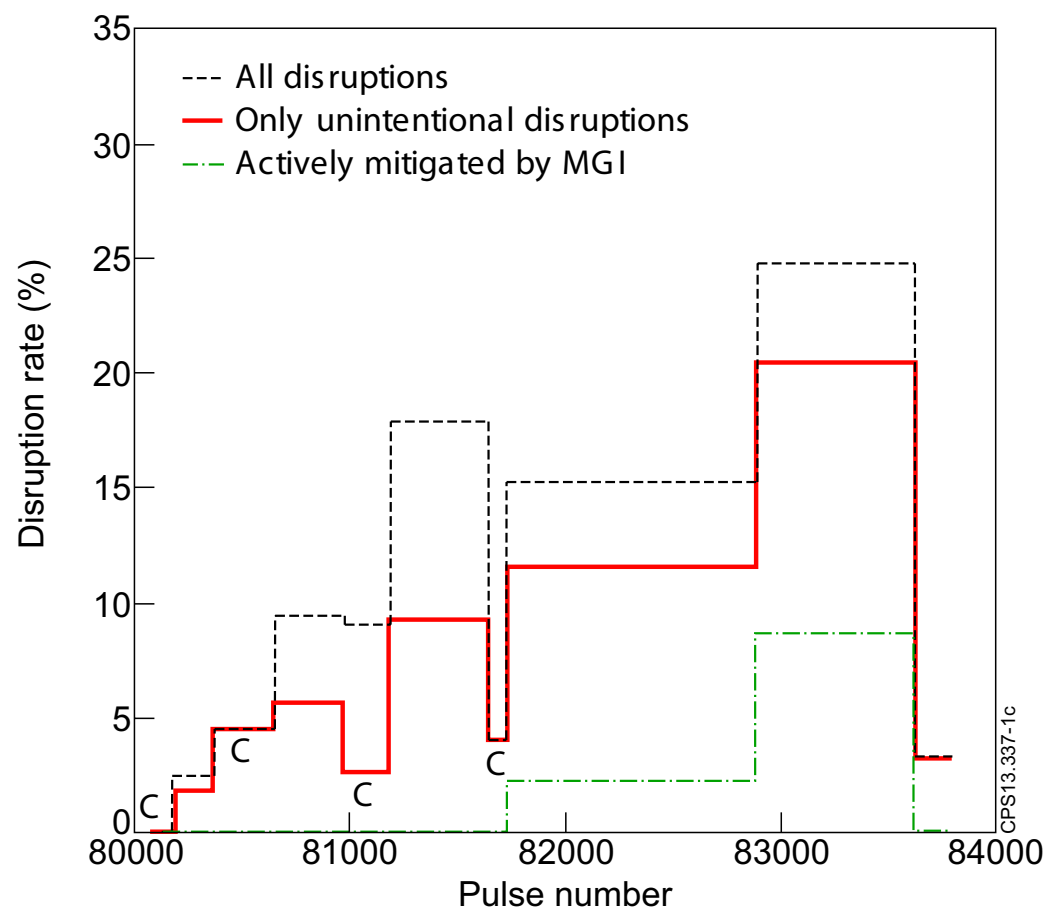

Figure 1: The unintentional and total disruption rate for the various stages of the first operations with the ILW at JET. The commissioning phases are labelled with a c, additionally the fraction of discharges that had a disruption mitigated by massive gas injection is given. 


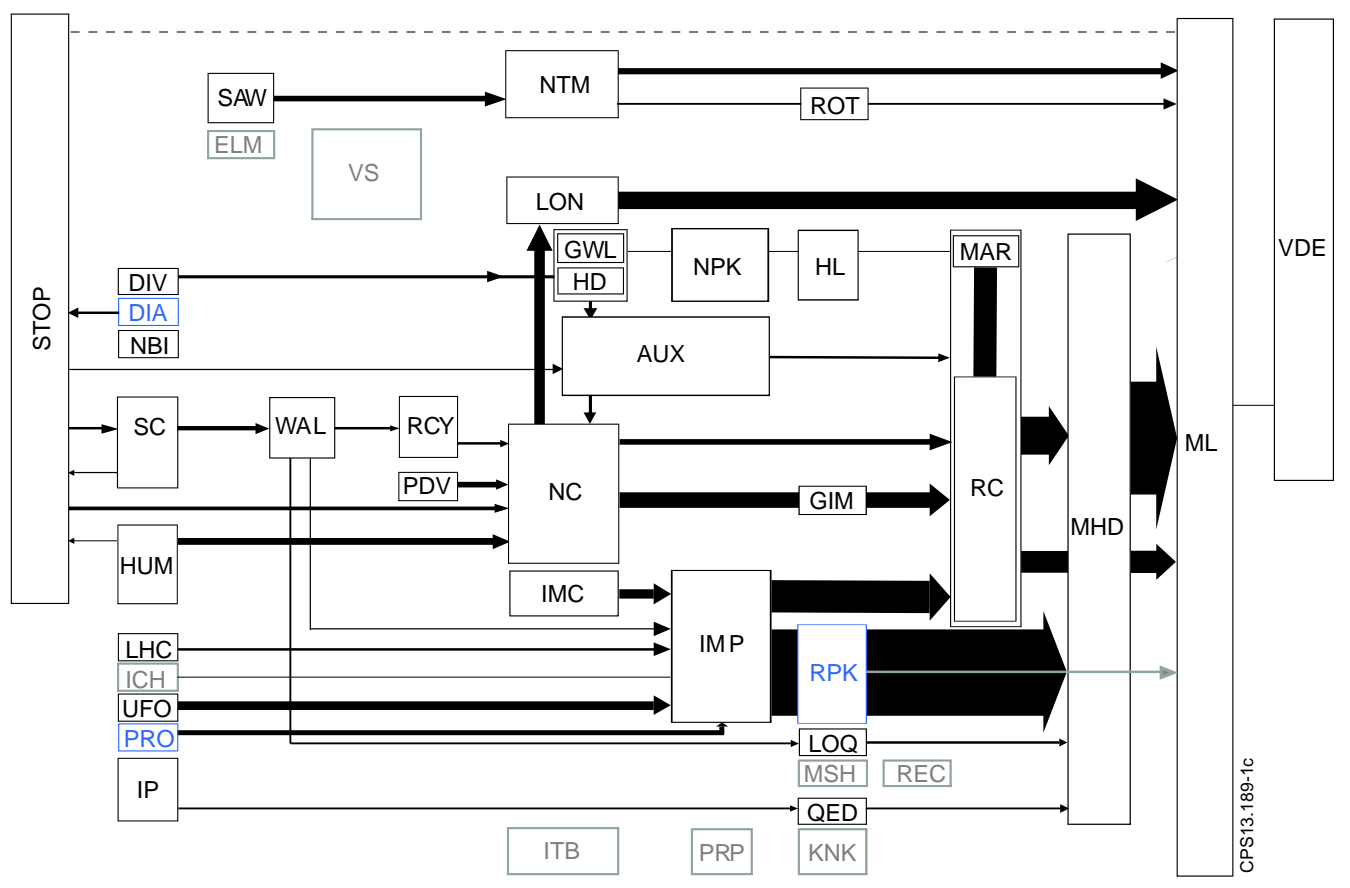

Figure 2: A schematic overview, showing the statistics of the sequence-of-events up to the (first) thermal quench for 275 unintentional disruptions at JET during the period 2011 to 2012. The width of each arrow indicates the number of cases found in the database. For comparison with the carbon wall operations, the MHD $\rightarrow$ ML arrow width is kept the same as that used in figure 4 in ref. [12]. Table 1 and 2 explain the node labels. Those nodes in grey were absent in 2011-2012, while those in blue are new on the graph (RPK: radiation peaking, PRO: reciprocating probe, DIA: diagnostic failure) 


\begin{tabular}{lc}
\hline a) Physics problem & Label \\
\hline General (rotating) $\mathrm{n}=1$ or $2 \mathrm{MHD}$ & $\mathrm{MHD}$ \\
Mode Lock & ML \\
Low q or q95 2 & LOQ \\
Edge q close to rational ( $>2)$ & QED \\
Large sawtooth crash & SAW \\
Neo-classical tearing mode & NTM \\
Internal kink mode & KNK \\
Reconnection & REC \\
& \\
\hline Radiative collapse $\left(\mathrm{P}_{\text {rad }}>\mathrm{P}_{\text {in }}\right)$ & RC \\
MARFE & MAR \\
Greenwald limit $\left(\mathrm{n}_{\mathrm{GW}}\right)$ & GWL \\
High density operation (near $\left.\mathrm{n}_{\mathrm{GW}}\right)$ & HD \\
Radiation peaking & RPK \\
& \\
\hline Too low density (and low q) & LON \\
H to L back-transition & HL \\
Strong density peaking & NPK \\
Too strong internal transport barrier & ITB \\
Strong pressure profile peaking & PRP \\
Negative central magnetic shear & MSH \\
Large edge localised mode $(E L M)$ & ELM \\
Vertical displacement event & VDE \\
\hline
\end{tabular}




\begin{tabular}{lc}
\hline b) Technical problem & Label \\
& \\
\hline Impurity control problem & IMC \\
Influx of impurities & IMP \\
Density control problem & NC \\
Too much gas from gas injection & GIM \\
No (effective) pumped Divertor & DIV \\
Shape control problem & SC \\
Plasma too close to the wall & WAL \\
High recycling & RCY \\
Other real-time control problem & RTC \\
Emergency shut-down & STOP \\
Manual emergency stop by operator & SL \\
& \\
\hline Wrong validated density for feedback & PDV \\
Magnetic signal(s) error & MAG \\
Reciprocating probe & PRO \\
Na influx by Lithium beam diagnostic & LIB \\
Other diagnostic problem & DIA \\
& \\
\hline Too little auxiliary power & AUX \\
Too little torque / rotation & ROT \\
Problem with Neutral Beam Injection & NBI \\
Impurity release due to LHCD & LHC \\
Impurities from ICRH antennae & ICH \\
& \\
\hline Problem with vertical stability control \\
(Intentional) vertical kink & VS \\
Temperature too high in VS amplifier & VSK \\
Over-current in VS amplifier & VST \\
Other failure of VS amplifier & VSI \\
& VSA \\
\hline Human error & HUM \\
Too fast a current ramp-up & IP \\
Other power supply problem & PS \\
Unidentified impurity influx & UFO \\
Problems due to pellet iniection & PEL \\
Impurity influx by laser ablation & ABL \\
& \\
\hline No clear cause & NON \\
\hline
\end{tabular}

Table 1: List of physics instabilities and limits or technical problems related to JET disruptions found during the period of 2000 to 2012, as explained in detail in ref. [12], with a new addition in italic, as discussed in section IV. The second column gives the label used in figure 2. 


\begin{tabular}{lccc}
\hline JET Disruption Classes & $\begin{array}{c}2000-2010 \\
\%\end{array}$ & $\begin{array}{c}2007-2009 \\
\%\end{array}$ & $\begin{array}{c}2011-2012 \\
\%\end{array}$ \\
\hline Impurity (control problems) & 1.39 & 0.91 & 1.63 \\
Density control problems & 1.16 & 1.36 & 0.99 \\
Auxiliary power shut-down (H-L) & 0.74 & 0.41 & 0.07 \\
Too strong core radiation & & & 4.60 \\
Fast emergency shut-down & 0.71 & 0.38 & 0.11 \\
Neo-classical tearing mode & 0.61 & 0.39 & 0.50 \\
Shape control problems & 0.45 & 0.20 & 0.11 \\
Current ramp-up & 0.44 & 0.19 & 0.11 \\
(Low density) Error field mode & 0.42 & 0.43 & 0.81 \\
Strong internal transport barrier & 0.38 & 0.14 & 0.00 \\
Vertical stability control problem & 0.34 & 0.52 & 0.04 \\
Greenwald limit & 0.18 & 0.10 & 0.00 \\
\hline No clear classification & 0.62 & 0.23 & 0.39 \\
\hline
\end{tabular}

Table 2: Comparison of the occurrence of different JET disruption classes as a fraction of the number of discharges above $\mathrm{I}_{\mathrm{p}}=1 \mathrm{MA}$, i.e. $1 \%$ means, $1 \%$ of the discharges disrupted due to the specified class. The first column set gives the average over the period from 2000-2011, comprising 22243 discharges and 1654 disruptions as discussed in ref. [12]. The second column shows the data for the final carbon wall campaign from 2007 to 2009, having 6907 discharges and 364 disruptions, which can be compared directly with the third column that shows the average for the ILW campaign from 2011 to 2012 with 2824 discharges and 273 disruptions. For this campaign a new disruption class, due to too strong core radiation, has been added (in italic). 


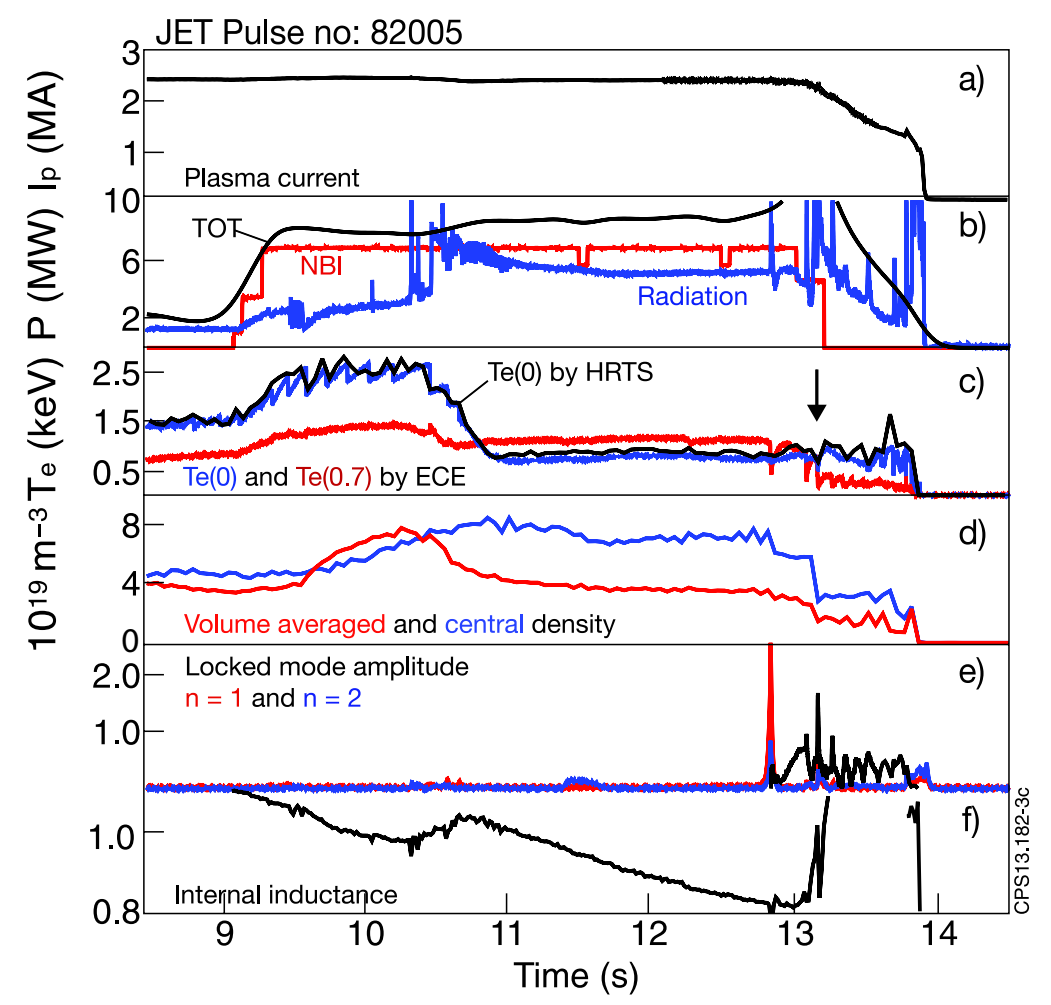

Figure 3: A summary of events of a characteristic disruption due to high- $Z$ impurity accumulation and a peaked radiation profile. a) The Plasma current. b) The total input and neutral beam injection (NBI) power only compared to the total radiative power. c) The core temperature and that at normalised radius of $\rho=0.7$ as measured by electron cyclotron emission (ECE) spectroscopy and high resolution Thomson scattering (HRTS). The (first) thermal quench is marked by an arrow. d) The volume averaged and central density as measured by HRTS. e) The amplitudes of $n=1$ and $n=2$ and the locked mode amplitudes. f) The internal inductance. 


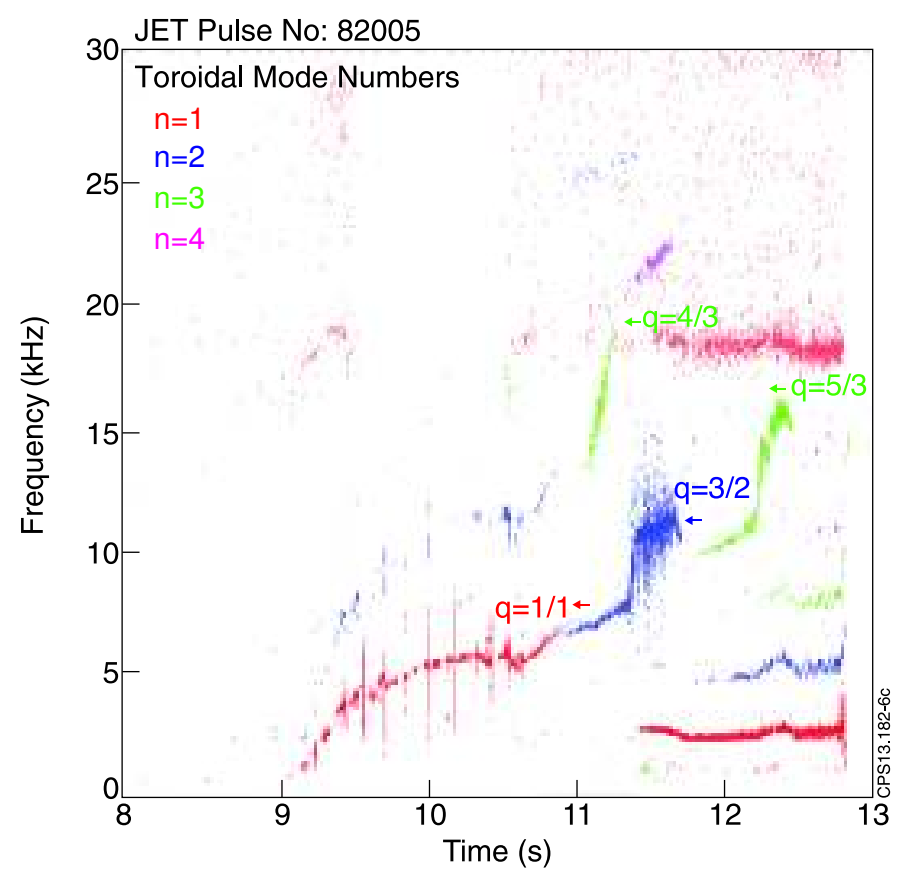

Figure 4: Spectrogram summarising the $n=1,2,3$ and 4 MHD activity in the final stages of the JET pulse no. 82005 (see figure 3). The arrows give the times for which CRONOS calculated the central q to increase above the respective values. 


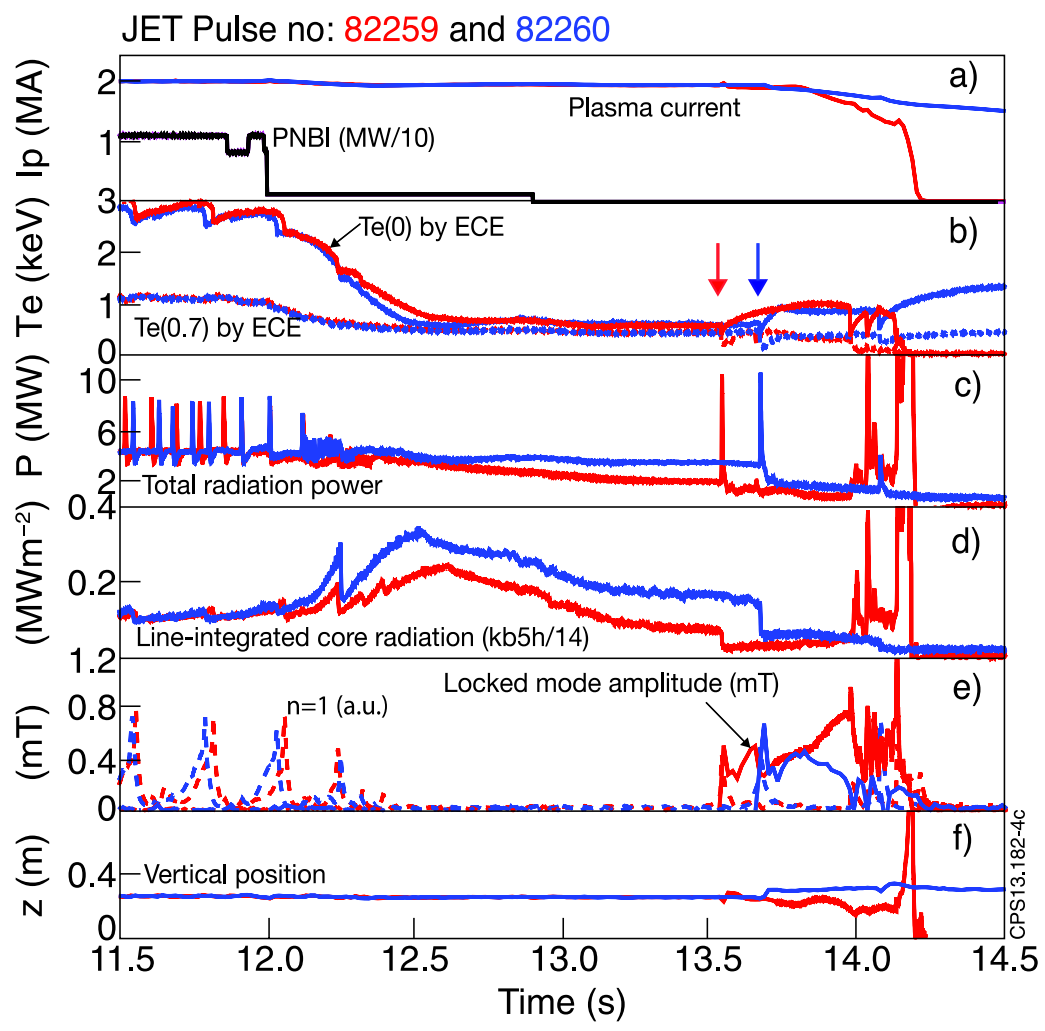

Figure 5: Comparison of two nearly identical thermal quenches (marked by the arrows), one that develops a VDE and current quench while the other improves and results in a soft landing. a) The plasma current. b) The central temperature and that measured at 0.7 of the minor radius, as measured by the heterodyne Electron Cyclotron Emission (ECE) spectrometer. c) The total radiated power as measured by the JET bolometer. d) The radiation seen by JET bolometer channel, viewing horizontally through the plasma centre. e) The $n=1$ and locked mode amplitude shown by the dashed and solid curve, respectively. f) The vertical plasma position. 

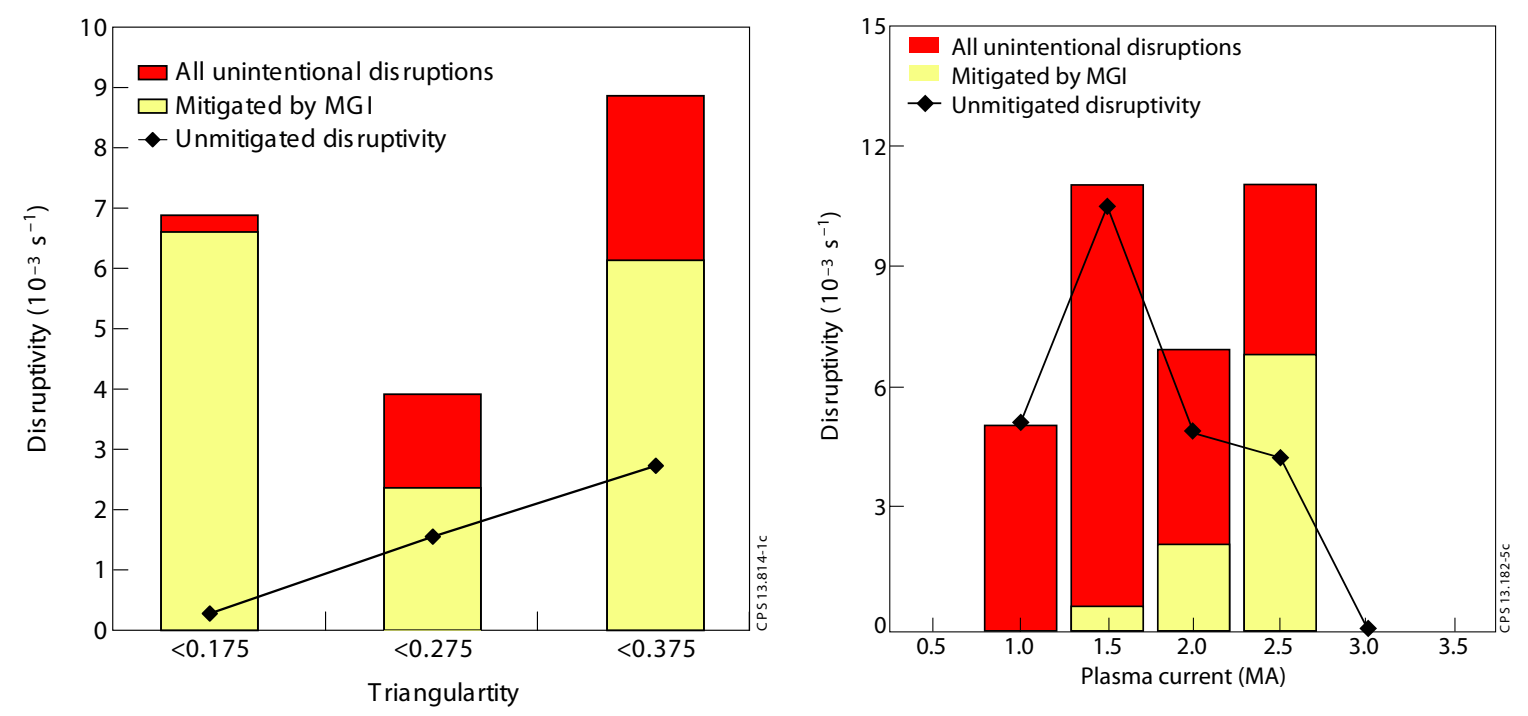

Figure 6: a) The disruptivity as a function of the triangularity, b) and as a function of plasma current, for all unintentional and mitigated disruptions in 2011-2012. 

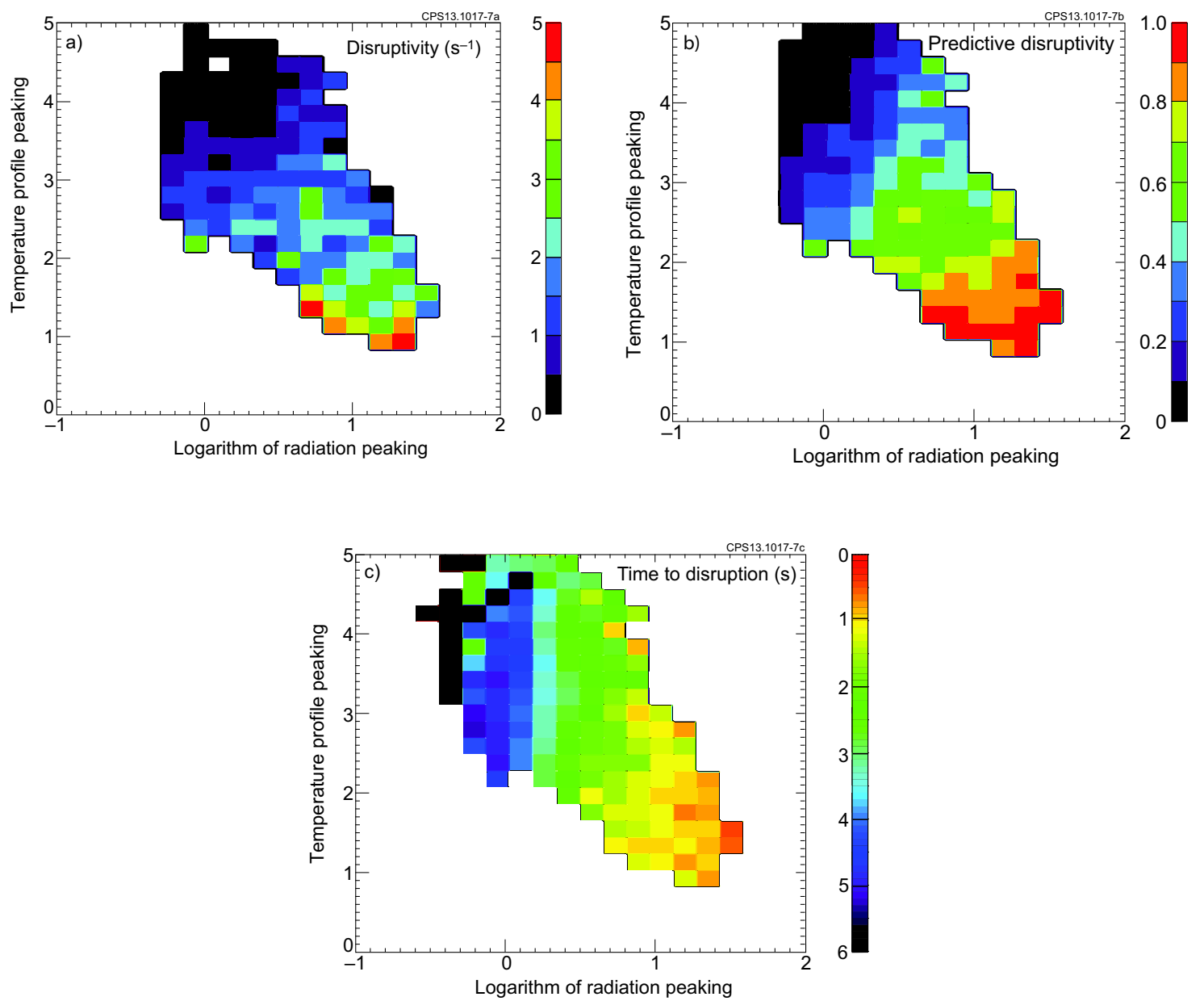

Figure 7: a) The disruptivity over 2011-2012 only considering disruptions due to high radiation peaking, as a function of the radiation and temperature profile peaking. b) The predictive disruptivity for the same parameter range. c) The average duration up to the thermal quench. In order to have statistical relevance only those parameter areas are shown for which at least $1.875 \mathrm{~s}$ of operation was achieved during 2011-2012. 

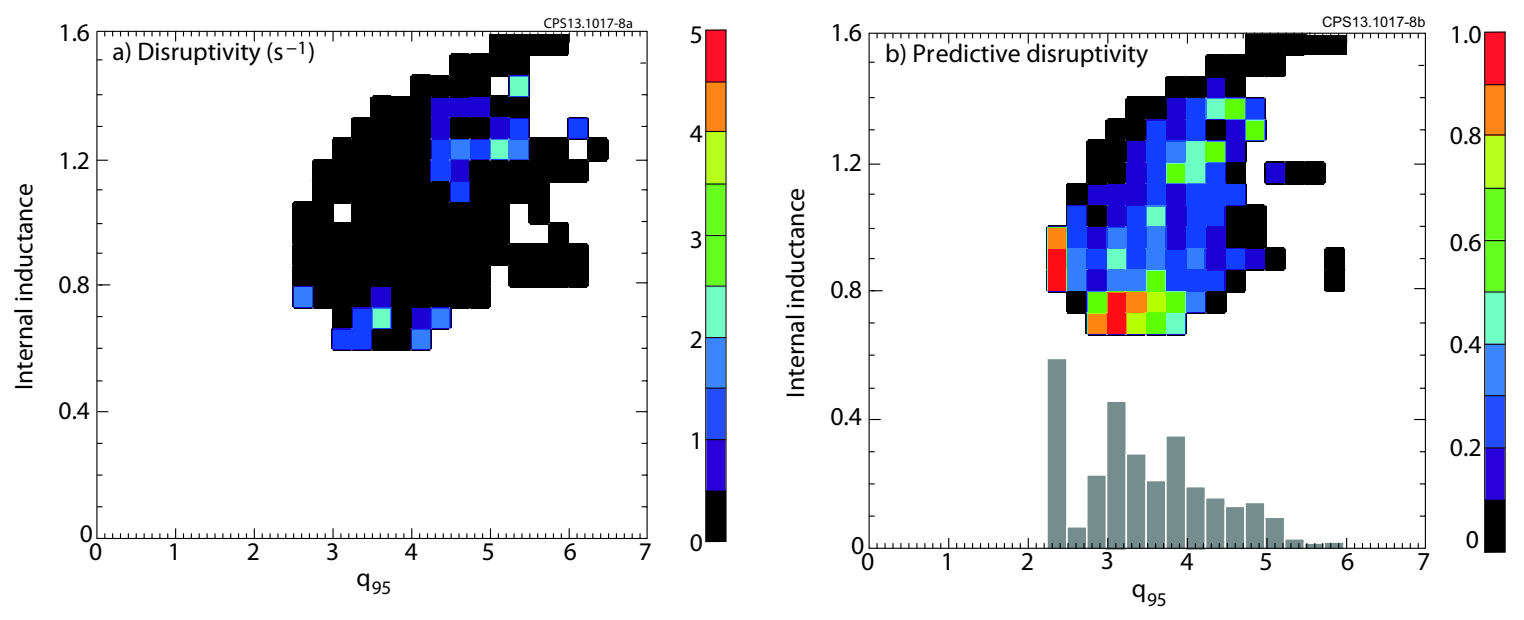

Figure 8: a) The disruptivity as a function of the edge safety factor $\left(\mathrm{q}_{95}\right)$ and the internal inductance using the same dataset as used for figure 7. b) The predictive disruptivity. The inset histogram gives the average values of predictive disruptivity versus $\mathrm{q}_{95}$ only, in arbitrary units. 

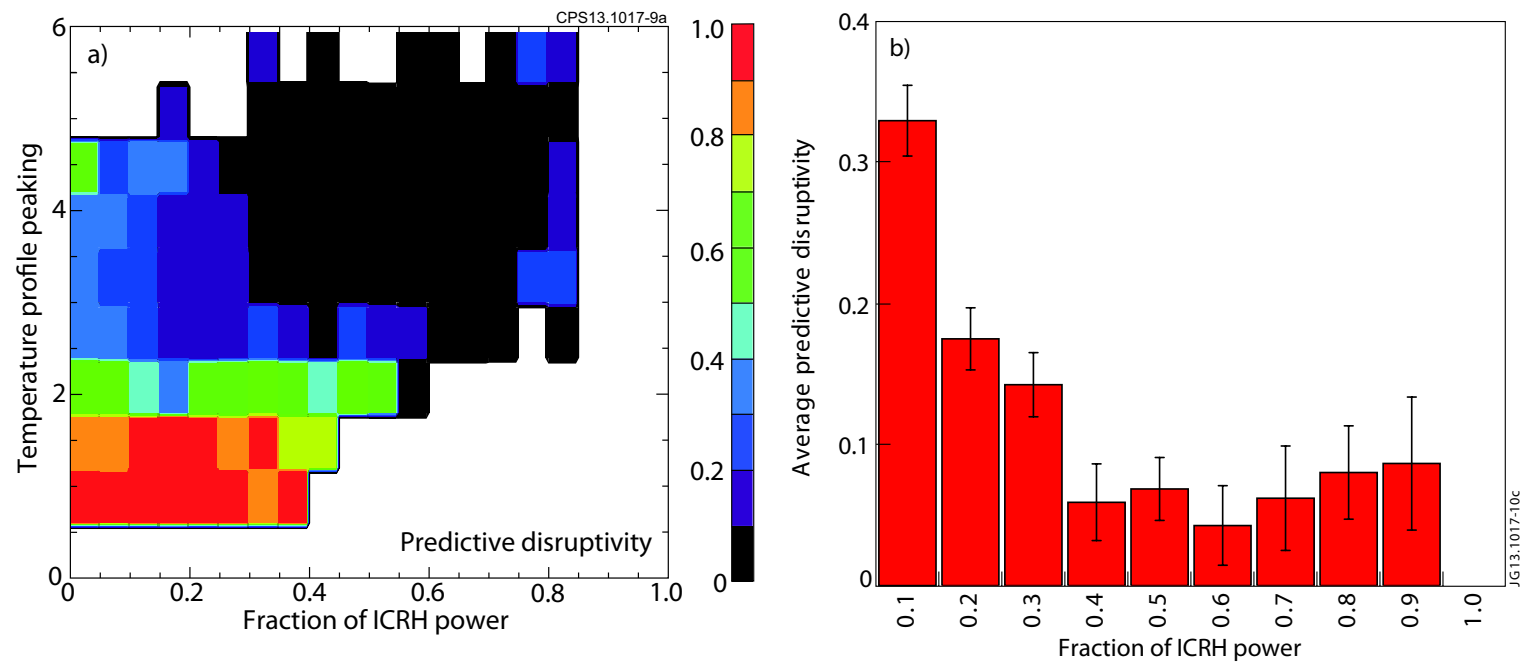

Figure 9: a) The predictive disruptivity as function of the fraction of ICRH power, i.e. $\mathrm{f}_{\mathrm{ICRH}}=\mathrm{P}_{\mathrm{ICRH}} /\left(\mathrm{P}_{\mathrm{ICRH}}+\mathrm{P}_{\mathrm{NBI}}+\mathrm{P}_{\mathrm{OHMIC}}\right)$, and the peaking of the temperature profile. The calculation was carried out using an extended dataset, comprising the same set as used for figure 7 and 8 , enlarged with data from the first period of operation in 2013 (up to JET pulse no: 85335). b) A slice of the previous graph showing the average predictive disruptivity for a fixed range of temperature profile peaking (from 3 to 4 ) as a function of $\mathrm{f}_{\mathrm{ICRH}}$. 